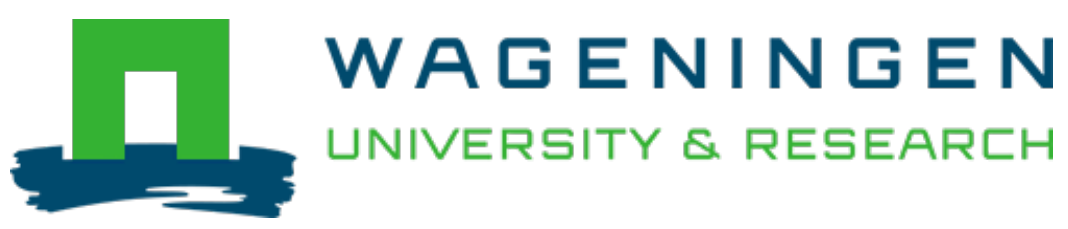

\title{
Vanillyl alcohol oxidase
}

Enzymes

Ewing, Tom A.; Gygli, Gudrun; Fraaije, Marco W.; Berkel, Willem J.H.

https://doi.org/10.1016/bs.enz.2020.05.003

This article is made publicly available in the institutional repository of Wageningen University and Research, under the terms of article $25 \mathrm{fa}$ of the Dutch Copyright Act, also known as the Amendment Taverne. This has been done with explicit consent by the author.

Article $25 \mathrm{fa}$ states that the author of a short scientific work funded either wholly or partially by Dutch public funds is entitled to make that work publicly available for no consideration following a reasonable period of time after the work was first published, provided that clear reference is made to the source of the first publication of the work.

This publication is distributed under The Association of Universities in the Netherlands (VSNU) 'Article 25fa implementation' project. In this project research outputs of researchers employed by Dutch Universities that comply with the legal requirements of Article $25 \mathrm{fa}$ of the Dutch Copyright Act are distributed online and free of cost or other barriers in institutional repositories. Research outputs are distributed six months after their first online publication in the original published version and with proper attribution to the source of the original publication.

You are permitted to download and use the publication for personal purposes. All rights remain with the author(s) and / or copyright owner(s) of this work. Any use of the publication or parts of it other than authorised under article $25 \mathrm{fa}$ of the Dutch Copyright act is prohibited. Wageningen University \& Research and the author(s) of this publication shall not be held responsible or liable for any damages resulting from your (re)use of this publication.

For questions regarding the public availability of this article please contact openscience.library@wur.nl 


\title{
Vanillyl alcohol oxidase
}

\author{
Tom A. Ewing ${ }^{a}$, Gudrun Gyglib ${ }^{b}$ Marco W. Fraaije ${ }^{c}$, \\ Willem J.H. van Berkel ${ }^{\mathrm{d}, *}$ \\ ${ }^{a}$ Wageningen Food \& Biobased Research, Wageningen University \& Research, Wageningen, The Netherlands \\ ${ }^{\mathrm{b}}$ Institute for Biological Interfaces, Karlsruhe Institute of Technology, Karlsruhe, Germany \\ ${ }^{c}$ Molecular Enzymology, University of Groningen, Groningen, The Netherlands \\ ${ }^{\mathrm{d}}$ Laboratory of Food Chemistry, Wageningen University \& Research, Wageningen, The Netherlands \\ ${ }^{*}$ Corresponding author: e-mail address: willem.vanberkel@wur.nl
}

\section{Contents}

1. Discovery of VAO

2. Initial characterization and physiological role 2

3. Substrate scope and catalytic mechanism 3

4. Crystal structure 9

5. Novel flavoprotein family 12

6. Mechanism of covalent flavinylation 12

7. Functional role of active site residues 15

8. Enzymatic synthesis of natural vanillin 18

9. The $\mathrm{VAO} / \mathrm{PCMH}$ family in the post-genomic era 19

References $\quad 26$

\begin{abstract}
This review presents a historical outline of the research on vanillyl alcohol oxidase (VAO) from Penicillium simplicissimum, one of the canonical members of the VAO/PCMH flavoprotein family. After describing its discovery and initial biochemical characterization, we discuss the physiological role, substrate scope, and catalytic mechanism of VAO, and review its three-dimensional structure and mechanism of covalent flavinylation. We also explain how protein engineering provided a deeper insight into the role of certain amino acid residues in determining the substrate specificity and enantioselectivity of the enzyme. Finally, we summarize recent computational studies about the migration of substrates and products through the enzyme's structure and the phylogenetic distribution of VAO and related enzymes.
\end{abstract}

\section{Discovery of VAO}

Like penicillin [1], VAO (EC 1.1.3.38) was discovered through serendipity. During studies on fungal lignin metabolism it was found that the ascomycete Penicillium simplicissimum, isolated from paper mill wastewater, 


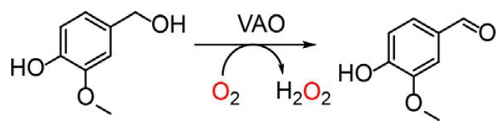

Fig. 1 Reaction of VAO with vanillyl alcohol.

grew on veratryl alcohol (3,4-dimethoxybenzyl alcohol) and oxidized this compound via an $\mathrm{NAD}(\mathrm{P})^{+}$-dependent veratryl alcohol dehydrogenase to veratryl aldehyde [2]. Attempts to purify the dehydrogenase were not successful but yielded a yellowish fraction that displayed oxidase activity toward vanillyl alcohol (4-hydroxy-3-methoxybenzyl alcohol) (Fig. 1).

Surprisingly, the intracellular VAO activity was not induced when $P$. simplicissimum was grown with vanillyl alcohol as sole carbon and energy source. This set the stage for a further investigation of the biochemical and structural properties of $\mathrm{VAO}$, which eventually led to the discovery of a new flavoprotein family. The development of this research line is described in this review. This manuscript will not focus on the potential biocatalytic applications of VAO. Readers interested in this aspect of the enzyme are referred to the following manuscripts [3-9].

\section{Initial characterization and physiological role}

Purification of VAO from veratryl alcohol grown P. simplicissimum CBS 170.90 cells revealed that the enzyme could be obtained in pure form through ammonium sulfate fractionation and three chromatographic steps [10]. VAO appeared to be active between $\mathrm{pH} 7$ and 12 with an optimum at $\mathrm{pH} 10$. Next to converting vanillyl alcohol to vanillin (4-hydroxy-3methoxybenzaldehyde; Fig. 1), the enzyme catalyzed the transformation of 4-hydroxybenzyl alcohol to 4-hydroxybenzaldehyde. Besides molecular oxygen, the enzyme could also use phenazine methosulfate as electron acceptor.

Analytical gel filtration, sedimentation velocity experiments and SDSPAGE showed that VAO is a homo-octamer with subunits of about $65 \mathrm{kDa}$. Cofactor analysis established that each VAO subunit contained a yellow, covalently bound prosthetic group, which was identified as $8 \alpha-$ $\left(N^{3}\right.$-histidyl)-FAD by $\mathrm{pH}$-dependent fluorescence experiments [10].

5 years after its discovery, experiments were initiated to find out more about the enigmatic physiological role of VAO. Immunochemistry showed that the oxidase co-localized in the peroxisomes and cytosol of 
P. simplicissimum, together with a newly identified dimeric catalaseperoxidase $[11,12]$. This suggested that the last three C-terminal residues (WKL) could serve as peroxisomal targeting signal in this fungus. It was also demonstrated that the production of VAO in P. simplicissimum was superfluous for the catabolism of veratryl alcohol and anisyl alcohol (4-methoxybenzyl alcohol) in $P$. simplicissimum, but essential for the catabolism of the rare $p$-cresol methylether 4-(methoxymethyl)phenol (Fig. 2) [14-16].

From these findings, it was proposed that 4-(methoxymethyl)phenol and closely related phenolic ethers, likely formed during the biodegradation of lignin, might be the physiological substrates of VAO [12,14]. Up to now, 4-(methoxymethyl)phenol is the only VAO substrate identified that induces expression of VAO in P. simplicissimum. However, in 1999, it was reported that VAO was induced in another ascomycete, Byssochlamys fulva V107, when the fungus was grown on vanillyl alcohol [17]. The exact role of VAO and related enzymes in the catabolism of aromatic phenols by ascomycetous fungi is still to be fully elucidated.

\section{Substrate scope and catalytic mechanism}

The VAO-catalyzed oxidation of 4-hydroxybenzyl alcohols and oxidative demethylation of 4-(methoxymethyl)phenol suggested that the enzyme might accept a broader range of 4-hydroxybenzylic compounds. This turned out to be the case (Table 1). Steady-state kinetics and product analysis revealed that $\mathrm{VAO}$ also catalyzed the oxidative deamination of vanillylamine (4-hydroxy-3-methoxybenzylamine) and 3,4 -dihydroxybenzylamine, the oxidation of the $\alpha$-hydroxy group of 4-hydroxy-3-methoxyphenylglycol and the oxidation of the $\alpha$-hydroxy group of various catecholamines [16]. Experiments with pure enantiomers of epinephrine and norepinephrine showed a clear preference for the $R$-isomers.

Of special interest was the unanticipated discovery that VAO was highly active with eugenol (4-allyl-2-methoxyphenol) and chavicol (4-allylphenol). These compounds were converted to the corresponding 4-hydroxycinnamyl alcohols (Table 1; Fig. 3) and it was hypothesized that the oxygen atom incorporated at the $\mathrm{C} \gamma$-atom of the 4-allylphenols was derived from water. Reaction performed with $\mathrm{H}_{2}^{18} \mathrm{O}$ and subsequent mass spectral analysis of the aromatic product confirmed the involvement of 


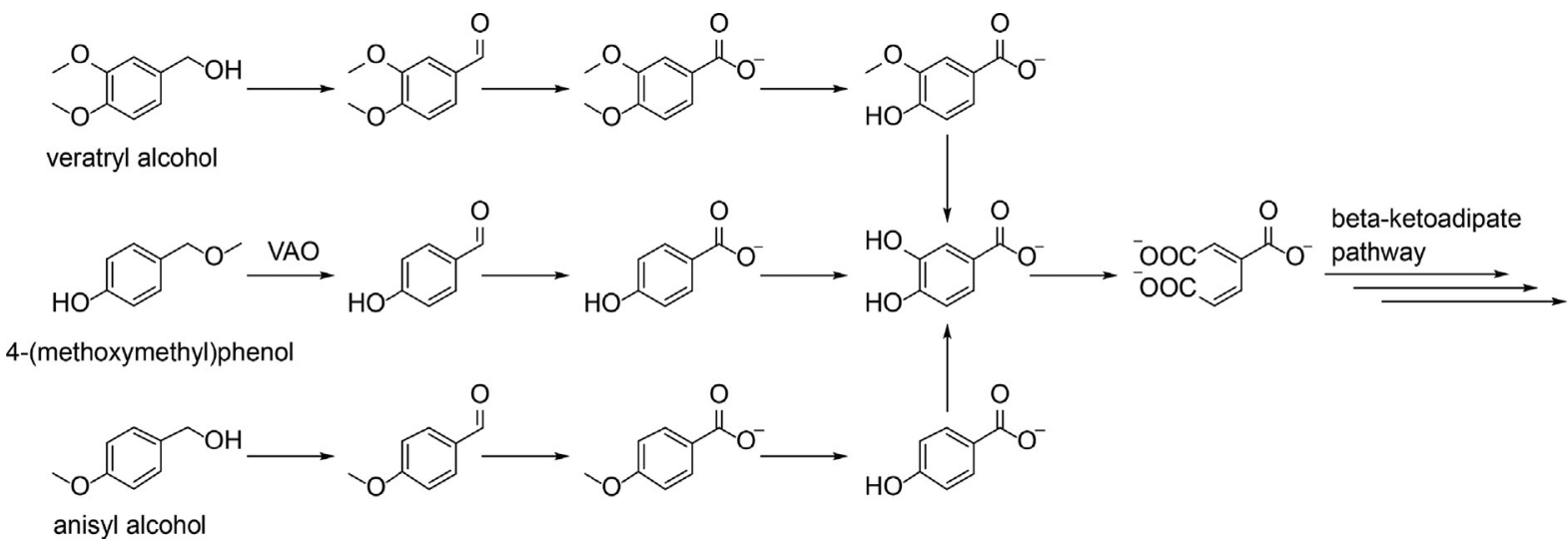

Fig. 2 Catabolism of veratryl alcohol, 4-(methoxymethyl)phenol and anisyl alcohol in Penicillium simplicissimum. VAO is not involved in the degradation of veratryl alcohol and anisyl alcohol, but catalyzes the first step in the degradation of 4-(methoxymethyl)phenol [13]. 
Table 1 Substrate scope of VAO from Penicillium simplicissimum.

\begin{tabular}{llllll} 
Substrate & $\begin{array}{l}\boldsymbol{k}_{\text {cat }} \\
\left(\mathbf{s}^{-1}\right)\end{array}$ & $\begin{array}{l}\boldsymbol{K}_{\mathbf{M}} \\
(\boldsymbol{\mu} \mathbf{M})\end{array}$ & $\begin{array}{l}\boldsymbol{k}_{\text {cat }} / \boldsymbol{K}_{\mathbf{M}} \\
\left(\mathbf{s}^{-1} \mathbf{m M}^{-1}\right)\end{array}$ & $\mathbf{p H}$ & References \\
\hline Vanillyl alcohol & 5.4 & 290 & 18.6 & 10 & {$[16]$} \\
\hline Vanillyl alcohol & 3.3 & 160 & 20.6 & 7.5 & {$[13]$} \\
\hline Eugenol & 13.0 & 4.9 & 2653 & 10 & {$[16]$} \\
\hline Chavicol & 6.5 & 4.8 & 1354 & 10 & {$[16]$} \\
\hline 4-(Methoxymethyl)phenol & 5.3 & 65 & 81.5 & 10 & {$[16]$} \\
\hline 4-(Methoxymethyl)phenol & 3.1 & 55 & 56.4 & 7.5 & {$[13]$} \\
\hline Vanillylamine & 1.3 & 240 & 5.4 & 10 & {$[16]$} \\
\hline Vanillylamine & 0.02 & 48 & 0.4 & 7.5 & {$[18]$} \\
\hline Metanephrine & 0.8 & 1600 & 0.5 & 10 & {$[16]$} \\
\hline Normetanephrine & 0.7 & 1400 & 0.5 & 10 & {$[16]$} \\
\hline Norepinephrine & 0.3 & 2900 & 0.1 & 10 & {$[16]$} \\
\hline 4- & 3.6 & 6000 & 0.6 & 10 & {$[16]$}
\end{tabular}

Hydroxy-3-methoxyphenylglycol

\begin{tabular}{llllll}
\hline$p$-Cresol & 0.005 & 31 & 0.2 & 7.5 & {$[19]$} \\
\hline$p$-Creosol & 0.07 & 50 & 1.4 & 7.5 & {$[18]$} \\
\hline 4-Ethylphenol & 2.7 & 7 & 386 & 10 & {$[20]$} \\
\hline 4-Ethylphenol & 2.5 & 9 & 278 & 7.5 & {$[19]$} \\
\hline 4-Propylphenol & 3.9 & 3 & 1300 & 10 & {$[20]$} \\
\hline 4-Propylphenol & 4.2 & 3.7 & 1135 & 7.5 & {$[19]$} \\
\hline 2-Methoxy-4-propylphenol & 4.8 & $<10$ & $>480$ & 10 & {$[20]$} \\
\hline 2-Methoxy-4-propylphenol & 4.9 & 6 & 817 & $7.5[21]$ \\
\hline 4-Isopropylphenol & 1.3 & 16 & 81.3 & 7.5 & {$[21]$} \\
\hline 4-sec-Butylphenol & 0.5 & 72 & 6.9 & 7.5 & {$[21]$} \\
\hline 4-n-Butylphenol & 1.2 & 2 & 600 & 7.5 & {$[21]$} \\
\hline 4-n-Pentylphenol & 0.3 & 8 & 37.5 & 7.5 & {$[21]$} \\
\hline 4-n-Heptylphenol & $<0.001$ & 42 & $<0.2$ & 7.5 & {$[21]$} \\
\hline 4-(3-Methylcrotyl)phenol & 1.4 & 65 & 21.5 & 7.5 & {$[21]$} \\
\hline
\end{tabular}


Table 1 Substrate scope of VAO from Penicillium simplicissimum.- - cont'd

\begin{tabular}{|c|c|c|c|c|c|}
\hline Substrate & $\begin{array}{l}k_{\mathrm{cat}} \\
\left(\mathrm{s}^{-1}\right)\end{array}$ & $\begin{array}{l}K_{\mathrm{M}} \\
(\mu \mathrm{M})\end{array}$ & $\begin{array}{l}k_{\mathrm{cat}} / K_{\mathrm{M}} \\
\left(\mathrm{s}^{-1} \mathrm{mM}^{-1}\right)\end{array}$ & $\mathrm{pH}$ & References \\
\hline $\begin{array}{l}\text { 4-(4-Hydroxyphenyl)-2- } \\
\text { butanone }\end{array}$ & 0.3 & 128 & 2.3 & 7.5 & {$[21]$} \\
\hline 5-Indanol & 0.5 & 77 & 6.5 & 7.5 & {$[21]$} \\
\hline $5,6,7,8$-Tetrahydronaphthol & 0.7 & 94 & 7.5 & 7.5 & {$[21]$} \\
\hline $\begin{array}{l}(R / S)-1-\left(4^{\prime} \text {-hydroxyphenyl }\right) \\
\text { ethanol }\end{array}$ & 3.0 & 30 & 100 & 7.5 & {$[21]$} \\
\hline$(R)-1-\left(4^{\prime}\right.$-hydroxyphenyl $)$ ethanol & 0.7 & 222 & 3.2 & 7.5 & {$[21]$} \\
\hline (S)-1-(4'-hydroxyphenyl)ethanol & 4.4 & 26 & 169 & 7.5 & {$[21]$} \\
\hline 2-(4'-Hydroxyphenyl)ethanol & 0.004 & 100 & 0.04 & 7.5 & {$[21]$} \\
\hline 3-(4'-Hydroxyphenyl)propanol & 0.1 & 8 & 12.5 & 7.5 & {$[21]$} \\
\hline 4-Cyclopentylphenol & $3.7^{\mathrm{a}}$ & & & & {$[22]$} \\
\hline
\end{tabular}

${ }^{\mathrm{a}} k_{\mathrm{obs}}$ for the oxidation of $2 \mathrm{mM} 4$-cyclopentylphenol by His-tagged recombinant VAO, at $\mathrm{pH} 7.5$. Steady-state kinetic parameters $k_{\text {cat }}$ and $K_{\mathrm{M}}$ were determined at $25^{\circ} \mathrm{C}$ in $50 \mathrm{mM}$ glycine $/ \mathrm{NaOH} \mathrm{pH} 10$, or $50 \mathrm{mM}$ potassium phosphate $\mathrm{pH} 7.5$.

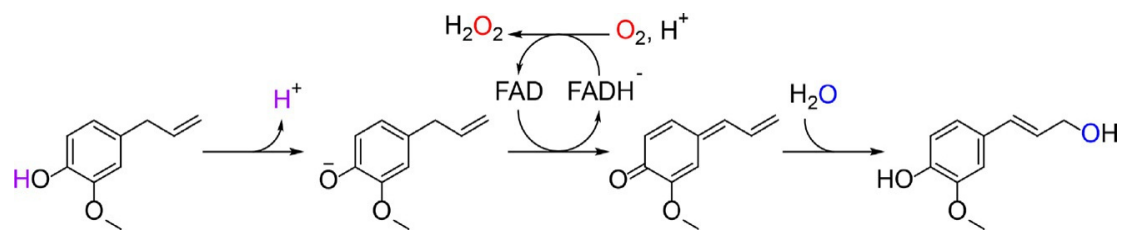

Fig. 3 Reaction of VAO with eugenol.

water as reactant in the production of coniferyl alcohol (4-hydroxy-3methoxycinnamyl alcohol) from eugenol [16].

Inhibition studies showed that coniferyl alcohol was a fairly strong competitive inhibitor of VAO $\left(K_{\mathrm{i}}=31 \pm 6 \mu \mathrm{M}, \mathrm{pH} 10\right)$. An even stronger inhibition was observed with isoeugenol (2-methoxy-4-propenylphenol; $\left.K_{\mathrm{i}}=13 \pm 5 \mu \mathrm{M}, \mathrm{pH} 10\right)$. Tight binding of isoeugenol was confirmed by difference absorption spectroscopy. Titration of the enzyme with this competitive inhibitor at various $\mathrm{pH}$ values yielded dissociation constants of the enzyme-isoeugenol complexes ranging from $K_{\mathrm{d}}=40 \pm 13 \mu \mathrm{M}$ at $\mathrm{pH}$ 4 to $K_{\mathrm{d}}=15 \pm 3 \mu \mathrm{M}$ at $\mathrm{pH} 10$. These experiments also showed that the intensities of the difference absorbance around $320 \mathrm{~nm}$ strongly increased between $\mathrm{pH} 4$ and 7 , indicative for the deprotonation of enzyme-bound 
isoeugenol with an apparent $\mathrm{p} K_{\mathrm{a}}$ value of 5.0 [16]. Based on these observations and the high $\mathrm{pH}$ optimum for turnover it was suggested that the enzyme facilitated oxidation of its substrates by the ability to stabilize quinoid intermediates due to resonance effects involving the phenolate form. In case of the reaction with 4-allylphenols, hydration at the $\mathrm{C} \gamma$-atom could be explained by a mechanism involving a $p$-quinone methide intermediate species, generated by the initial transfer of a hydride equivalent to the flavin cofactor, followed by the addition of water (Fig. 3).

Strong support for the proposed mechanism was obtained from monitoring the reductive half-reaction of VAO using stopped-flow diode array absorption spectroscopy [13]. Upon mixing the enzyme with 4-(methoxymethyl)phenol under anaerobic conditions, a decrease in absorption around $440 \mathrm{~nm}$, indicative for flavin reduction, was accompanied by a strong increase in absorption around $365 \mathrm{~nm}$, consistent with the generation of a $p$-quinone methide product intermediate (Fig. 4A).

When the reaction was followed for a longer period of time, a very slow decay of the high absorbance intermediate was observed, indicating that the $p$-quinone methide formed from 4-(methoxymethyl)phenol was highly stabilized in the enzyme active site as long as the flavin cofactor remained
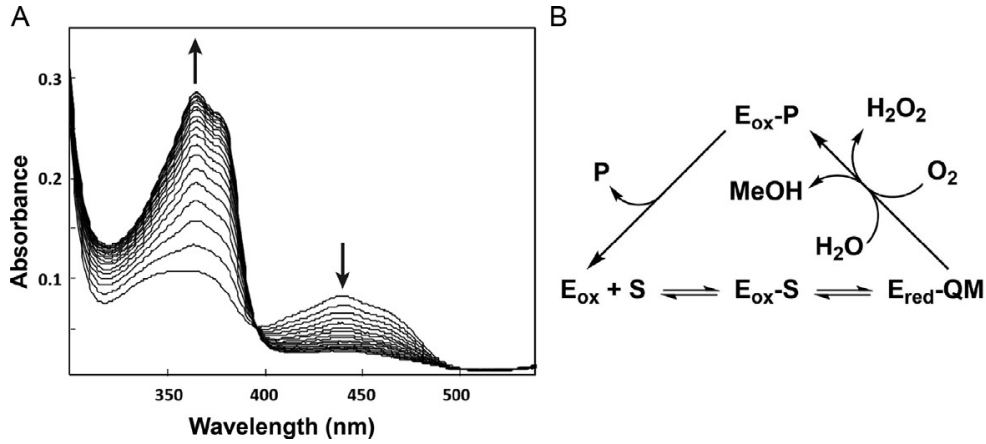

Fig. 4 Catalytic mechanism of the reaction of VAO with 4-(methoxymethyl)phenol. (A) Reaction of VAO with 4-(methoxymethyl)phenol under anaerobic conditions. Spectral changes observed upon mixing $7 \mu \mathrm{M}$ VAO with $500 \mu \mathrm{M} 4$-(methoxymethyl) phenol at $25^{\circ} \mathrm{C}$ in oxygen-free $50 \mathrm{mM}$ potassium phosphate buffer $\mathrm{pH} 7.5$, containing $0.1 \mu \mathrm{M}$ glucose oxidase and $10 \mathrm{mM}$ glucose. Spectra were recorded from 5.6 to $956.6 \mathrm{~ms}$ with intervals of $80 \mathrm{~ms}$. (B) Kinetic mechanism of the reaction of VAO with 4-(methoxymethyl)phenol. $\mathrm{E}_{\mathrm{OX}}$, oxidized VAO; $\mathrm{E}_{\mathrm{RED}}$, two-electron reduced VAO; $\mathrm{S}$, 4-(methoxymethyl)phenol substrate; $\mathrm{QM}$, para-quinone methide product intermediate; P, 4-hydroxybenzaldehyde product. Panels ( $A$ and B) Modified from M.W. Fraaije, W.J.H. van Berkel, Catalytic mechanism of the oxidative demethylation of 4-(methoxymethyl)phenol by vanillyl-alcohol oxidase, J. Biol. Chem. 272 (1997) 18111-18116. 
reduced. Upon reoxidation of the flavin through mixing with air, the $p$-quinone methide rapidly reacted with water to form the unstable hemiacetal product of 4-(methoxymethyl)phenol, which spontaneously decomposed to 4-hydroxybenzaldehyde and methanol. Isotopic labeling experiments with $\mathrm{H}_{2}{ }^{18} \mathrm{O}$ confirmed that the $p$-quinone methide intermediate was hydrated by the action of water.

Stopped-flow spectral analysis of the reductive half-reaction of VAO with vanillyl alcohol also showed the formation of a $p$-quinone methide intermediate. However, with the alcohol substrate, this species was quite unstable and rapidly decomposed to the final product vanillin. The instability of the vanillyl alcohol $p$-quinone methide was consistent with $\mathrm{H}_{2}{ }^{18} \mathrm{O}$ incorporation experiments, which showed that during the oxidation of vanillyl alcohol, water was not significantly involved in the formation of the aldehyde product [13].

From determining steady-state kinetic parameters and measuring the kinetics of the reductive and oxidative half-reactions, it could be established that the hydride transfer reactions of the oxidized enzyme with 4-(methoxymethyl)phenol and vanillyl alcohol were rate-limiting in overall catalysis and that the reaction of VAO with 4-(methoxymethyl)phenol was consistent with a ternary complex mechanism including formation of a reduced enzyme $p$-quinone methide complex and reoxidation of the reduced enzyme complex by molecular oxygen with the concomitant conversion of the intermediate to form the final product (Fig. 4B).

Subsequent studies revealed that $\mathrm{VAO}$ was also active with 4-alkylphenols (Table 1) and that the enzyme catalyzed the enantioselective hydroxylation of 4-ethylphenol, 4-propylphenol and 2-methoxy-4-propylphenol into the corresponding 1-(4'-hydroxyphenyl)alcohols with an ee of $94 \%$ for the $R$-enantiomers [20]. In agreement with the proposed mechanism for the enzymatic conversion of eugenol, it was established that the oxygen atom incorporated into the alcohol products was derived from water. Besides the alcohol products, also small amounts of vinylphenols and phenolic ketones were formed, pointing at competitive reaction pathways and consecutive oxidation steps [20]. The high ee observed for the formation of $(R)$-1-(4'-hydroxyphenyl)alcohols was partially explained by the fact that the $(S)$-isomers of the initially formed 1-(4'-hydroxyphenyl)alcohols were preferentially oxidized by VAO to the corresponding phenolic ketones [21].

The reactivity with short chain 4-alkylphenols was addressed further in kinetic studies [19]. It was found that VAO catalysis with 4-ethylphenol and 4-propylphenol followed an ordered sequential binding mechanism in 
which flavin reduction limited the turnover rate while the binary complex between the reduced enzyme and the $p$-quinone methide intermediate reacted rapidly with oxygen. With both 4 -alkylphenols, flavin reduction turned out to be a reversible process, with similar rates for the forward and backward reactions. A reversible reduction process was also observed in the reaction of VAO with $p$-cresol (4-methylphenol). However, with this compound, product formation was extremely slow due to impaired reoxidation of the flavin. As discussed below, this was caused by formation of a covalent adduct between $p$-cresol and the N5-atom of the FAD cofactor, resulting in suicide inhibition.

The VAO-mediated conversion of 4-alkylphenols was also studied with more bulky substrates [21]. It turned out that VAO accepted bicyclic substrates like 5-indanol and 5,6,7,8-tetrahydro-2-naphthol, and 4-alkylphenols with aliphatic side chains up to seven carbon atoms (Table 1). Medium-chain 4-alkylphenols were mainly converted to the corresponding 1-(4'-hydroxyphenyl)alkenes. The cis-trans stereochemistry of these reactions was strongly dependent on the nature of the alkyl side chain. The enzymatic conversion of 4-sec-butylphenol resulted in the production of 2-(4'-hydroxyphenyl)-sec-butanol and two (4'-hydroxyphenyl)sec-butene isomers. Later studies showed that VAO also catalyzed the oxidation of the bulky cycloalkylphenols 4-cyclopentylphenol and 4-cyclohexylphenol [22].

\section{Crystal structure}

To shed more light on the flavin-binding properties and catalytic features of VAO, its crystal structure was solved in the native state and in complex with several inhibitors [23,24]. The analysis of the threedimensional structure showed that the VAO octamer could be described as a tetramer of dimers. Each dimer showed extensive inter-subunit contacts, while the dimer-dimer contact area was limited to a restricted number of residues (Fig. 5A). The weak interaction between dimers was consistent with biochemical experiments, which showed that at low enzyme concentration, the VAO octamer partially dissociated into dimers [25].

The crystal structure at $2.5 \AA$ resolution also revealed that each VAO subunit consisted of a large FAD-binding domain (residues 6-270 and 500-600) and a small cap domain (residues 271-499) (Fig. 5B) [24]. The structure of the VAO subunit closely resembled the structure of the flavoprotein subunit of para-cresol methylhydroxylase from Pseudomonas putida NCIMB 9866 
A

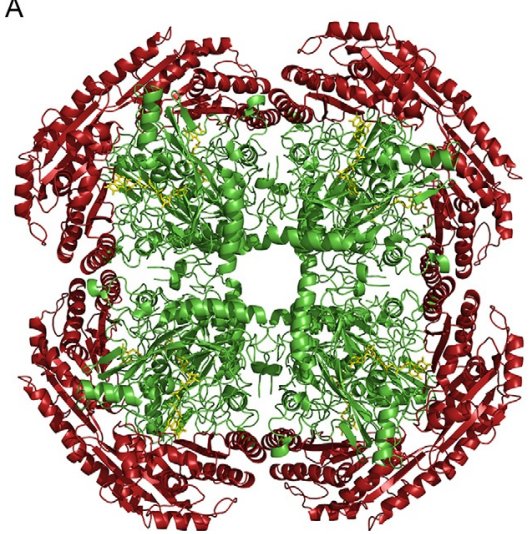

B

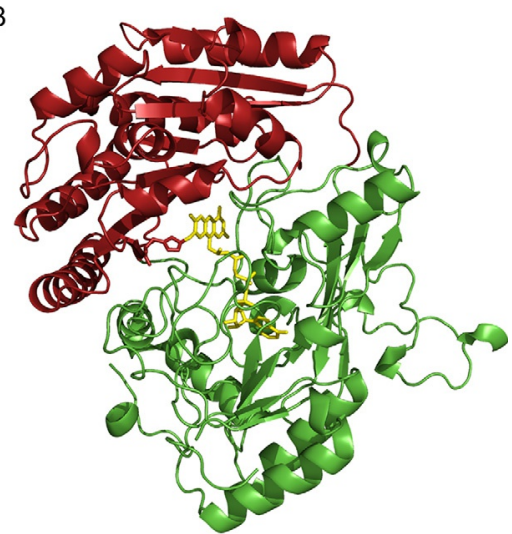

Fig. 5 Crystal structure of VAO. (A) VAO octamer. The structure is shown in cartoon representation with the FAD-binding domains shown in green and the substrate-binding cap domains in red. The FAD cofactors are shown as yellow sticks. Each quarter of the ring-like octameric structure corresponds to a tightly packed dimer, with the inter-dimer packing being more lose. (B) VAO subunit. The FAD-binding domain is shown in green and the substrate-binding cap domain in red. The flavin cofactor, shown in yellow, is covalently linked to His422 of the cap domain. Figures were prepared from PDB file IVAO [24].

(PCMH; EC 1.17.99.1) [26], but an in-depth comparison with this flavocytochrome had to await the crystallographic refinement of the PCMH structure [27].

The VAO structure confirmed the earlier finding [10] that the isoalloxazine ring of the flavin is covalently linked via its C8 methyl group to the N3-atom of a histidine, and furthermore showed that this residue (His422) is located in the cap domain. Of note is that VAO was the first enzyme of known structure containing an $8 \alpha-\left(N^{3}\right.$-histidyl $)-F A D$ linkage.

The substrate-binding site of VAO appeared to be located at the domain interface on the si-side of the flavin ring. Covered by the cap domain it formed a closed elongated cavity. In spite of the solvent inaccessibility, the inhibitors isoeugenol, 2-nitro-4-methylphenol and 4-(1-heptenyl)phenol did all bind to the native crystals without any significant conformational change. In case of 4-(1-heptenyl)phenol binding, no residual void was present in the active site, suggesting that the substrate specificity of VAO was dictated by a size-exclusion mechanism [24].

The crystal structure of the VAO-isoeugenol complex showed that the phenolic hydroxyl group of the inhibitor was hydrogen bonded to Tyr108, Tyr503 and Arg504 (Fig. 6). This provided a rationale for the low $\mathrm{pKa}$ of the 


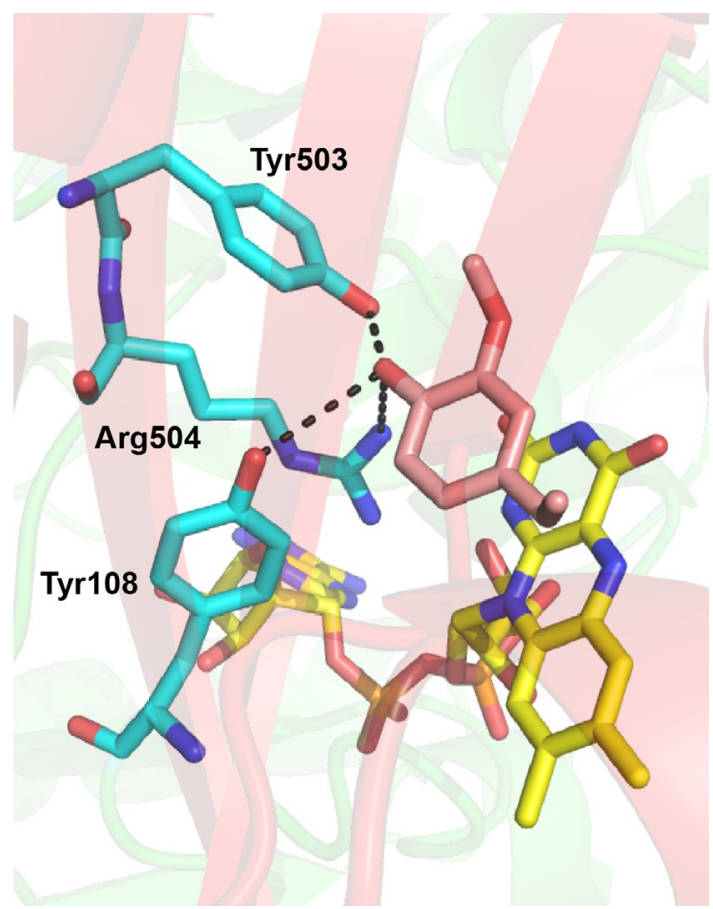

Fig. 6 Structure of phenolate-binding pocket of VAO. Tyr-108, Tyr-503 and Arg-504 are shown in stick representation with cyan carbon atoms, the competitive inhibitor isoeugenol with pink carbon atoms and the FAD cofactor with yellow carbon atoms. Nitrogen atoms are shown in blue, oxygen atoms in red and phosphorus atoms in orange. Potential hydrogen bonds between the amino acid residues of the phenolate-binding pocket and the phenolic hydroxyl group of isoeugenol are shown as black dashes. The protein backbone is shown in cartoon representation, with the FAD-binding domain in green and the substrate-binding domain in red. The figure was prepared from PDB file 2VAO [24].

enzyme-isoeugenol complex found previously with absorption difference spectroscopy [16] and strengthened the view that the anion hole formed by Tyr108, Tyr503 and Arg504 is instrumental to substrate deprotonation. The structure of the VAO-isoeugenol complex also revealed that the propenyl group of the bound inhibitor, located at $3.5 \AA$ distance from the N5-atom of the flavin, pointed toward Asp170. This suggested that Asp170 might act as an active site base, either deprotonating the $p$-quinone methide in case of substrates being dehydrogenated, or activating the water attacking the substrates undergoing hydroxylation [24].

The crystal structure of the VAO-p-cresol complex provided a plausible explanation for the slow reaction and suicide inhibition observed with this 
substrate [19]. The electron density map of the VAO-p-cresol complex revealed a strong peak located on the si-side of the flavin cofactor, which was connected to the flavin N5 position by a stretch of continuous electron density. Single crystal microspectrometry showed that reduction of the flavin by $p$-cresol took more than 2 days, while dithionite reduced the crystalline enzyme in a few seconds. The flavin spectral changes observed during the reaction with $p$-cresol were consistent with solution studies [19] and indicative for the formation of a covalent adduct between the N5-atom of the flavin and the methyl group of $p$-cresol [24].

\section{Novel flavoprotein family}

Along with the three-dimensional structure determination, the vao gene from $P$. simplicissimum was cloned, sequenced and expressed in Aspergillus niger and Escherichia coli [28]. Sequence comparison indicated that the FAD-binding domains of $\mathrm{VAO}$ and $\mathrm{PCMH}$ had features in common with several other flavoenzymes such as D-lactate dehydrogenase from yeast, berberine-bridge enzyme ( $S$-reticuline oxidase) from the California poppy, hexose oxidase from the red alga Chondrus crispus, L-gulono- $\boldsymbol{\gamma}-$ lactone oxidase from rat, glycolate oxidase from Escherichia coli and alkyldihydroxyacetone phosphate synthase from human and pig [29]. A more extensive search with these proteins revealed a group of 12 sequences of homologous proteins with known function and 32 sequences representing enzyme homologs or unidentified gene products. All these proteins were about 500 amino acids in length and shared extensive sequence homology in the N-terminal half and at the very end of the C-termini. Based on these results and inspection of the crystal structures of VAO and $\mathrm{PCMH}$, it was concluded that these proteins represented a novel oxidoreductase family sharing a conserved FAD-binding domain. Members of this flavoprotein family were found in all kingdoms of life, where they participate in highly diverse metabolic processes [29]. Intriguingly, many of the VAO-related enzymes were found or predicted to contain a covalently bound flavin, a rather unusual mode of flavin binding present in about $10 \%$ of the known flavoproteins.

\section{Mechanism of covalent flavinylation}

Elucidation of the amino acid sequence and crystal structure of VAO allowed for protein engineering studies to address the function of specific 
amino acid residues by site-directed mutagenesis. Because at the end of the last century relatively little was known about the mechanisms of covalent flavinylation and the role of the covalent attachments [30], an obvious target to start with was His422, which links the FAD cofactor of VAO to its cap domain [24].

To learn more about the functional role of the $8 \alpha-\left(N^{3}\right.$-histidyl $)-F A D$ bond, three His422 variants (H422A, H422T and H422C) were produced and characterized [31]. All three purified variants contained a tightly, noncovalently bound FAD cofactor and showed about $10 \%$ of the activity of wild-type VAO. Elucidation of the crystal structure of H422A established that deletion of the covalent interaction between enzyme and flavin did not result in any significant structural change and that the binding mode of the competitive inhibitor isoeugenol remained the same.

Stopped-flow kinetics of the reaction of H422A with 4-(methoxymethyl)phenol revealed no change in catalytic mechanism (see [25]), but a 10-fold decrease in flavin reduction rate. Redox potential determinations showed a remarkably high midpoint redox potential $\left(E_{\mathrm{m}}\right)=+55 \mathrm{mV}$ for wild-type VAO, and a considerably lower $E_{\mathrm{m}}=-65 \mathrm{mV}$ for H422A. From this it was concluded that the covalent interaction between the isoalloxazine ring of the flavin and the enzyme facilitated flavin reduction and that the formation of a histidyl-FAD bond in VAO and other flavoenzymes might have evolved as a way to contribute to the enhancement of their oxidation power [31].

To address the mechanism of covalent flavinylation in VAO in further detail, another histidine (His61), located in the FAD domain in the close vicinity of His422, was changed to a threonine [32]. The H61T variant did bind FAD non-covalently $\left(K_{\mathrm{d}}=1.8 \mu \mathrm{M}\right)$ and was again about 10-fold less active with 4-(methoxymethyl)phenol than wild-type VAO. Crystallographic analysis showed that dissociation of the non-covalently bound FAD did not change the structural properties of H61T, which were highly similar to that of the wild-type enzyme. These results indicated that binding of the FAD cofactor to the VAO apoprotein followed a lock-andkey mechanism and that covalent flavinylation was an autocatalytic process in which His61 together with His422 promoted deprotonation and subsequent attack on the $8 \alpha$-methyl group of the flavin isoalloxazine ring [32].

Analytical gel filtration revealed that the H61T apoprotein easily dissociated into dimers. Because electrospray ionization mass spectrometry (ESI-MS) had provided useful information about the oligomerization behavior of holo-VAO $[33,34]$, this provided the unique opportunity to 
address the role of cofactor binding in the supramolecular assembly of VAO by this technique [35]. It was found that at $4 \mu \mathrm{M}$ protein concentration, apoH61T was mainly present as a dimer, and that both FAD and 5'-ADP binding induced octamerization. From this it was argued that small conformational changes in the ADP-binding pocket of the dimeric enzyme were transmitted to the protein surface promoting octamerization [35].

Several years later, ESI-MS was used to even better understand the mechanism by which VAO covalently incorporated the FAD cofactor [36]. To reach this goal, the VAO apoprotein was produced in a riboflavin auxotrophic Escherichia coli strain. Mixing purified apo-VAO with FAD resulted in fast non-covalent complex formation followed by a slow increase in enzyme activity and full covalent incorporation of the cofactor. The maximum rate and $K_{\mathrm{M} \text {,FAD }}$ for the covalent flavinylation reaction were estimated to be $0.13 \pm 0.02 \mathrm{~min}^{-1}$ and $2.3 \pm 0.2 \mu \mathrm{M}$, respectively. The nanoflow ESI-MS analysis of formation of holo-VAO showed that the fast, non-covalent binding of FAD shifted the monomer/dimer/octamer equilibrium toward the dimeric and octameric species. Further spectroscopic experiments supported an earlier proposal made for monomeric sarcosine oxidase [37] that the autocatalytic flavinylation process proceeded via a reduced flavin intermediate (Fig. 7). This mechanism has been proposed to apply generally for His-, Tyr-, and Cys-linked flavoproteins [38].
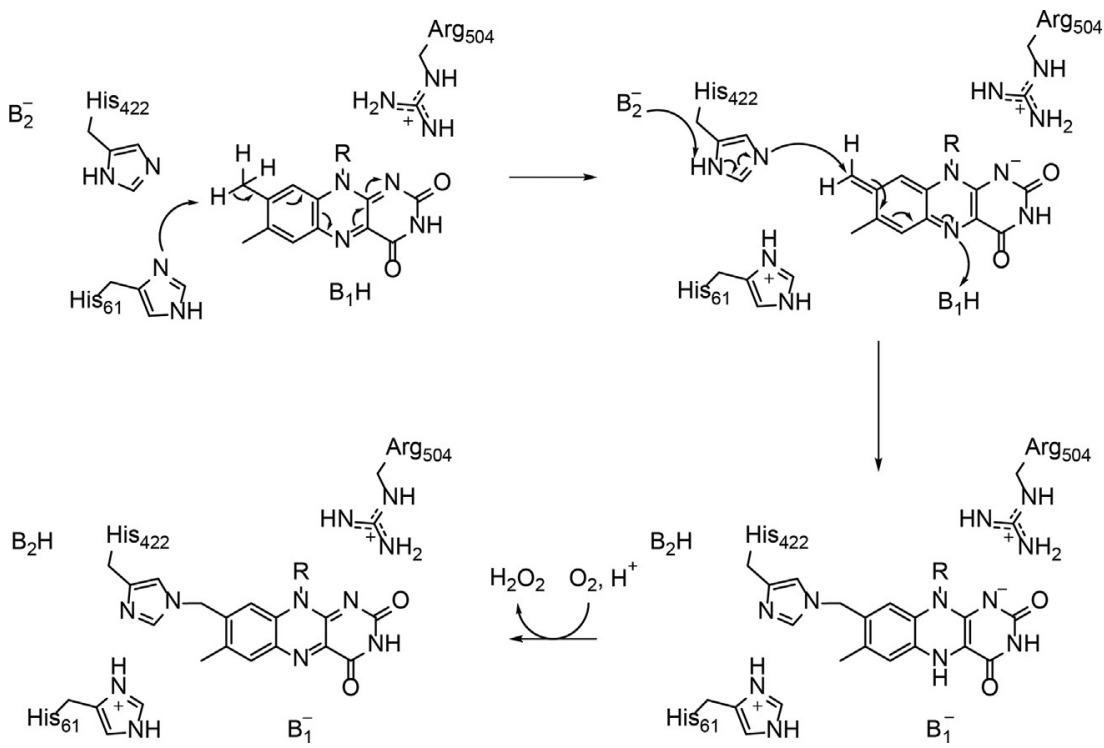

Fig. 7 Mechanism for autocatalytic covalent flavinylation of VAO as proposed in [36]. 


\section{Functional role of active site residues}

As mentioned above, the crystal structure of VAO suggested that Asp170, located near the N5-atom of the flavin isoalloxazine ring, might act as an active site base. This hypothesis was tested through the production and characterization of several Asp170 variants [39]. Purified D170A and D170N appeared to contain 50\% and 100\% non-covalently bound FAD, suggesting that Asp170 is involved in the process of autocatalytic flavinylation. The D170E and D170S mutant proteins were found to contain covalently tethered FAD. Crystallographic analysis of D170S showed that the replacement of Asp by Ser did not introduce significant structural changes. Kinetic characterization of the reactions of the Asp170 variants with 4-(methoxymethyl)phenol revealed that Asp170 was essential for rapid flavin reduction. D170E was 50 times less active, while the other Asp170 variants were 1000-fold less active than wild-type VAO. The midpoint redox potentials of D170E $(+6 \mathrm{mV})$ and D170S $(-91 \mathrm{mV})$ were far lower than that of the wild-type enzyme $(+55 \mathrm{mV})$, supporting the idea that Asp170 interacts with flavin N5, thereby increasing the oxidation power of $\mathrm{VAO}$ [39].

The functional role of Asp170 in VAO catalysis was addressed further by studying the reactivity of D170E and D170S with 4-alkylphenols [40]. The catalytic efficiency of D170E with these substrates was about one order of magnitude lower than that of wild-type enzyme, predominantly because of lowered turnover rates. D170S was hardly active with straight-chain 4-alkylphenols, due to formation of air-stable covalent flavin N5 adducts. Interestingly, D170S showed significant activity with 4-isopropylphenol and 4-sec-butylphenol, suggesting that adduct formation was prevented by steric constraints.

Product analysis revealed that D170S mimicked wild-type VAO in converting 4-ethylphenol and 4-propylphenol mainly to the corresponding 1-(4'-hydroxyphenyl)alcohols. However, in contrast to wild-type enzyme, D170S converted medium-chain and branched-chain 4-alkylphenols also to the corresponding alcohols. This indicated that the small side chain of Ser170 increased the accessibility of water to the active site and that hydration of the $p$-quinone methide intermediate could also occur in the absence of an active site base [39]. The product selectivity of D170E strikingly differed from D170S and wild-type VAO by displaying a strong preference for the production of $1-\left(4^{\prime}-\right.$ hydroxyphenyl)alkenes. This supported the 
idea that the bulkiness of the Glu170 side chain limited the accessibility of water to the planar quinone methide intermediate [40]. Interestingly, a similar result could be achieved by reducing the water activity of the reaction medium [41].

Inspired by the intriguing properties of the Asp170 variants $[39,40]$ and the opposite enantioselectivities of VAO [20] and PCMH [42], we searched for differences in the active sites of both enzymes. From the PCMH structural analysis it was proposed that Glu380, the equivalent of Asp170 in VAO, might activate the water involved in substrate conversion [27]. However, in PCMH another acidic residue (Glu427) was situated in close vicinity of the reactive carbon of bound $p$-cresol at the opposite face of the phenolic substrate. Because VAO lacked an acidic residue at this position (Thr457), it was hypothesized that this structural variation might explain the opposite stereochemistry of VAO and PCMH in the reaction with 4-ethylphenol.

To test this hypothesis, the properties of the single variants D170A, D170S and T457E, and of the double variants D170A/T457E and D170S/T457E were evaluated [43]. All variants contained covalently bound FAD and their midpoint redox potentials varied from $-91 \mathrm{mV}$ for D170S [39] to $+20 \mathrm{mV},+22 \mathrm{mV}$ and $+31 \mathrm{mV}$ for T457E, D170A/T457E and D170S/T457E, respectively. This was the first indication that Glu457 could replace Asp170 in redox catalysis. Except for T457E, all enzyme variants showed rather low turnover rates with 4-(methoxymethyl)phenol. Nevertheless, both D170A/T457E and D170S/T457E were far more active with this substrate than D170A and D170S, underlining indeed that Glu457 could, to a certain extent, take over the crucial role of Asp170 in catalysis.

Product analysis of the reactions with 4-ethylphenol revealed that all VAO variants catalyzed the formation of 1-(4'-hydroxyphenyl) ethanol in high yield and that only minor amounts of the side product 4-vinylphenol were formed. Like wild-type enzyme, T457E preferentially converted 4-ethylphenol to the $(R)$-enantiomer of 1-(4'-hydroxyphenyl) ethanol (Fig. 8A), suggesting that Asp170 still directed the water attack to the quinone methide intermediate. D170A and D170S were less $(R)$-selective with ee values of $26 \%$ and $50 \%$, respectively. Gratifyingly, D170A/T457E and D170S/T457E were (S)-selective with ee values of $20 \%$ and $80 \%$, respectively. The $(S)$-selectivity of the double mutants confirmed that Glu457 had taken over the role of Asp170 in activating the water for stereospecific attack (Fig. 8B) [43].

Elucidation of the crystal structure of D170S/T457E in complex with the substrate analog trifluoromethylphenol clearly established that the two 
A
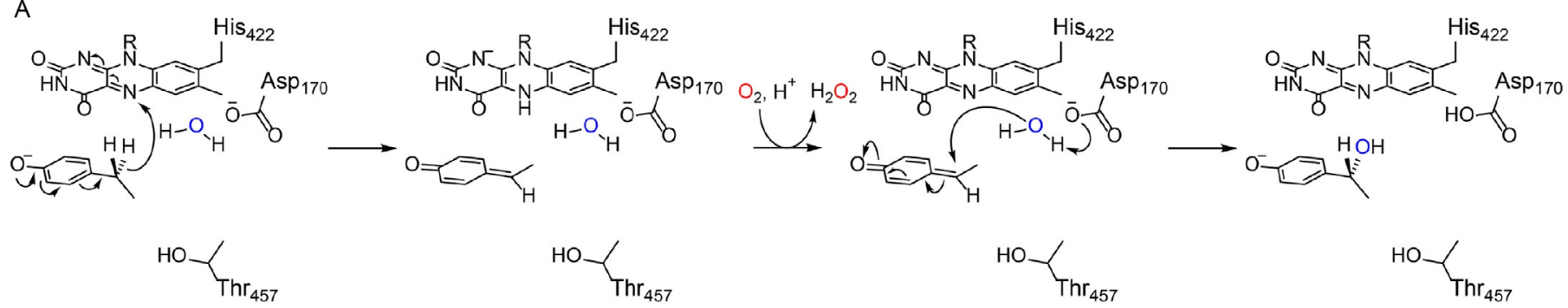

B
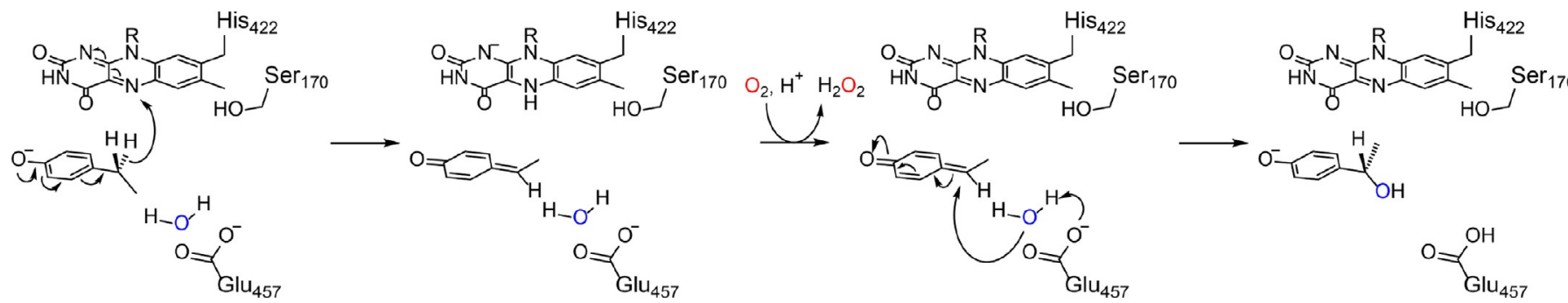

Fig. 8 Enantioselectivity of VAO for the hydroxylation of 4-ethylphenol. (A) (R)-enantiopreference of wild-type VAO. (B) (S)-enantiopreference of D170S/T457E variant. 
amino acid replacements had not caused any significant protein conformational change. The carboxylate side chain of the newly introduced Glu457 residue pointed toward the $\mathrm{C} \alpha$-atom of bound trifluoromethylphenol at a distance of $3.5 \AA$, providing strong support for its role in functioning as an active site base [43].

In a more recent study, we produced Y108F, Y503F and Y108F/Y503F variants to address the precise role of Tyr108 and Tyr503 in substrate activation [44]. $\mathrm{pH}$-dependent stopped-flow kinetics of the reductive halfreactions revealed that wild-type VAO reacted rapidly with the phenolate form of chavicol and more slowly with the phenolic form, and that the reaction with deprotonated chavicol was impaired in the Tyr variants. In agreement with this, the competitive inhibitor isoeugenol bound predominantly in its phenolate form to wild-type VAO and predominantly in its phenolic form to the Tyr variants. Based on these results and supporting crystal structures of $\mathrm{Y} 108 \mathrm{~F}$ and $\mathrm{Y} 503 \mathrm{~F}$, it was concluded that both active site tyrosines are responsible for the activation of VAO substrates [44].

\section{Enzymatic synthesis of natural vanillin}

VAO catalyzes the conversion of vanillyl alcohol to the widely used flavor compound vanillin. With the increasing demand for natural products (see, e.g., [45]), we considered the possibility to apply VAO for the enzymatic synthesis of vanillin from a natural feedstock [18]. Vanillyl alcohol is not widely available in nature, and thus not suited for this purpose. Yet, a potential feedstock for vanillin is creosol (2-methoxy-4-methylphenol), which is the major component of creosote, obtained from heating wood or other plant material. We anticipated that creosol would be converted by $\mathrm{VAO}$ in a two-step oxidation process via the intermediate formation of vanillyl alcohol. Indeed, when the reaction of $1 \mu \mathrm{M}$ VAO with $100 \mu \mathrm{M}$ creosol was followed by HPLC, we observed that under optimal reaction conditions ( $\mathrm{pH}$ 7.5), the initially formed vanillyl alcohol became smoothly fully converted into vanillin [18]. At concentrations of creosol above $150 \mu \mathrm{M}$, the conversion rate decreased because creosol competitively inhibited the conversion of the intermediate product vanillyl alcohol.

Steady-state and stopped-flow kinetic experiments performed at $\mathrm{pH} 7.5$ showed similar kinetics as described for the reaction with $p$-cresol [19], with the reductive half-reaction being reversible and partially limiting catalysis. However, when the reaction was performed at $\mathrm{pH} 10$, the optimum $\mathrm{pH}$ for the reaction of VAO with vanillyl alcohol, nearly no conversion of 
creosol was observed [18]. Absorption and fluorescence spectral analysis revealed that this was due to an increased stabilization of the covalent adduct between creosol and the reduced flavin cofactor.

In summary, the slow hydroxylation of creosol to vanillyl alcohol was limiting the VAO-mediated synthesis of "natural" vanillin, mainly also because of the formation of an air-stable covalent flavin-substrate adduct. Recent quantum chemical modeling of $\mathrm{VAO}$ has indicated that the short side chain of $p$-creosol enables Asp170 to initiate adduct formation through attacking the proton at flavin $\mathrm{N} 5 \mathrm{H}$, and that with the bulkier vanillyl alcohol, Asp170 is unable to attack the reduced flavin [46].

The poor activity of $\mathrm{VAO}$ with 4-methylphenols inspired us to start a random mutagenesis procedure to generate enzyme variants with enhanced reactivity to creosol [47]. After a single round of manganese-based errorprone PCR, seven positive clones were selected for further investigation. Among the purified enzymes, four variants with a single amino acid change (I238T, F454Y, E502G and T505S) distal from the active site cavity showed an up to 40-fold increase in catalytic efficiency with creosol. Further characterization revealed that this was due to a lower stability of the covalent flavin-creosol adduct, stimulating "natural" vanillin formation. Interestingly, the VAO variants showed similar activities with vanillyl alcohol and 4-(methoxymethyl)phenol as the wild-type enzyme, but were nearly inactive with $p$-cresol. Quite remarkable was also the considerable drop in catalytic efficiency (up to 200-fold) for the reaction with eugenol. Crystallography studies showed that all variants had conserved threedimensional structures and that the replaced amino acid residues were not located in close vicinity of the substrate-binding site. These results led us to conclude that the amino acid substitutions had introduced subtle changes in electrostatic and hydrogen bond interactions, and possibly enzyme dynamics, and that remote residues, not readily predicted by rational design, can modulate the substrate specificity of VAO [47]. We therefore anticipate that a more extensive random mutagenesis process could generate VAO variants with a much higher activity for creosol. Alternatively, genome mining might yield novel VAO enzymes with such properties $[48,49]$.

\section{The VAO/PCMH family in the post-genomic era}

With the boost in genome sequencing at the start of this century, the number of known $\mathrm{VAO} / \mathrm{PCMH}$ family members rapidly increased. In 2005, the first family member (glucooligosaccharide oxidase) was reported 
that bound the FAD cofactor in a bicovalent mode [50]. In 2008, phylogenetic analysis established that all thirteen newly discovered 6-Scysteinyl-8 $\alpha-N^{1}$-histidyl FAD-containing enzymes of the steadily growing $\mathrm{VAO} / \mathrm{PCMH}$ family were evolutionary closely related [51], and that VAO and PCMH clustered in a separate subgroup together with eugenol hydroxylase (EUGH) from Pseudomonas species [52,53] and eugenol oxidase (EUGO) from Rhodococcus jostii RHA1 [54]. Next to berberine-bridge enzyme-like synthases (reticuline oxidases) [55,56], the subgroup of bicovalently bound flavoproteins contained several oxidases that were active on polysaccharides [57-59]. All these double-anchored enzymes displayed relatively high redox potentials, stressing the impact of bicovalent flavinylation $[38,59,60]$. As of 2017 , the VAO/PCMH family encompasses 115 members, which can be divided into 11 phylogenetically distinct subfamilies [61]. Among these 115 flavoenzymes, one-third has a known threedimensional structure, and more than two-thirds contain a covalently bound FAD cofactor.

As mentioned above, $\mathrm{VAO}$ and $\mathrm{PCMH}$ reside in a rather small subgroup of the VAO/PCMH family. Members of this subgroup catalyze the C $\alpha-$ oxidation of para-substituted phenols through the initial formation of a para-quinone methide intermediate [61]. They contain a conserved TyrTyr-Arg triad for activating the substrate and usually bind the FAD cofactor monocovalently via a loop that is close to the C-terminus of the protein. This anchoring mode differs from other members of the superfamily, where the covalent linkages are located closer to the $\mathrm{N}$-terminus [59]. In VAO and EUGO, the flavin is anchored to a histidine, while in PCMH and EUGH, the flavin is covalently linked to a tyrosine.

Two members of the 4-phenol oxidizing (4PO) subgroup were reported to catalyze the oxidative decarboxylation of $\mathrm{N}$-substituted tyrosine derivatives yielding $\mathrm{N}$-acyl tyrosine antibiotics. FeeG, obtained from an unidentified soil microbe, was shown to produce long-chain $\mathrm{N}$-acyl tyrosines [62], while CndG from the soil-dwelling bacterium Chondromyces crocatus was demonstrated to catalyze the post-assembly line modification of prechondrochloren to chondrochloren [63]. CndG was reported to contain non-covalently bound FAD [63], in agreement with the absence of conservation of the abovementioned anchoring residues.

In 2016, the crystal structure of EUGO from the actinobacterium Rhodococcus jostii RHA1 was elucidated [64]. In addition to eugenol and vanillyl alcohol, this close homolog of VAO converted a broad range of 4-substituted phenols, but was poorly active with 4-(methoxymethyl) 
phenol and 4-alkylphenols [22,54,64]. Complexation with isoeugenol, coniferyl alcohol and vanillin revealed that the solvent-inaccessible substrate-binding pocket of EUGO was highly similar to that of VAO, with the ligand 4-hydroxy group pointing to the Tyr-Tyr-Arg anion-binding site. However, isoeugenol was observed to bind in a flipped orientation with the ligand methoxy group occupying a different niche in the enzyme active site. From this it was concluded that in VAO, the side chain of Phe424 (replaced by Gly392 in EUGO) prevented this mode of isoeugenol binding. In agreement with this supposition, EUGO turned out to be active with 4-allylsyringol (4-allyl-2,6-dimethoxyphenol), while VAO was not $[22,64]$. The I427A variant of EUGO appeared to be even more efficient in producing sinapyl alcohol (4-hydroxy-3,5-dimethoxycinnamyl alcohol) from 4-allylsyringol, which was exploited to obtain gram amounts of the valuable lignan syringaresinol 4,4'-(1S,3aR,4S,6aR)-tetrahydro- $1 H, 3 H-$ furo[3,4-c]furan-1,4-diylbis(2,6-dimethoxyphenol) in a cascade reaction with horseradish peroxidase [65]. With the current focus on lignin valorization, we expect that VAO and EUGO might develop as valuable biocatalysts for the production of lignin derivatives. A good example presents the above-discussed VAO-mediated conversion of creosol to vanillin.

While VAO is an octamer, EUGO is a dimer [54]. From comparing both three-dimensional structures, we hypothesized that a loop at the dimerdimer interface in VAO might be responsible for dimer association [66]. Deletion of this loop resulted in active VAO dimers, but introduction of the loop in EUGO was not sufficient to induce octamerization. Bioinformatics analysis showed that the loop was conserved in several putative fungal members of the $4 \mathrm{PO}$ subgroup, but never present in putative bacterial members $[48,66]$. It will be of interest to see if the marked differences in substrate specificity between VAO and EUGO [22,64] will also hold for newly characterized homologs.

In 2017, we performed Monte Carlo based Protein Energy Landscape Exploration (PELE) simulations to learn more about the dynamic features of $\mathrm{VAO}$, and in particular how substrates and products enter and exit the active site [67]. From the VAO structure, no path for solvent or ligand access to the active site was visible [24]. However, from the structure of the enzyme-cresol complex of PCMH [27] and the EUGO structure in complex with isoeugenol [64], it was suggested that a funnel-shaped cavity, running from the protein surface along the dimer interface and branching off into each subunit, might represent a path for the diffusion of substrates into the solvent-inaccessible active sites. PELE simulations with the VAO dimer 
indeed identified an entry and exit path at the subunit interface as the most likely migration path for phenolic ligands (Fig. 9) [67]. Interestingly, the amino acid residues involved in this path are well conserved in VAO, EUGO and PCMH, indicating that dimerization of these enzymes is functionally linked to ligand migration.

Two additional exit paths, leading through the cap domain and the FAD-binding domain of $\mathrm{VAO}$ required substantial movement of bulky amino acid side chains [67]. It was also found that protonated creosol freely migrated through the subunit interface portal to the active site, while deprotonated creosol did not, and that His466 and Tyr503 might act as swinging concierges, providing access to the substrate-binding pocket.

Migration via the flavin re-side was predicted to be the shortest entrance and exit path for the co-ligands dioxygen and hydrogen peroxide (Fig. 9) [67]. Flavin re-side specificity for dioxygen diffusion was also predicted for other $\mathrm{VAO} / \mathrm{PCMH}$ family members [68-70]. With alditol oxidase, molecular dynamics simulations identified funnel-shaped migration paths that led dioxygen to an Ala105 gatekeeper residue that controlled access to the dioxygen-binding pocket in proximity of the reactive $\mathrm{C} 4 \mathrm{a}$ atom of the flavin isoalloxazine ring [68]. Changing this alanine in L-galactono-1,4lactone dehydrogenase into a glycine (A113G) strongly increased the oxygen reactivity of this enzyme [69]. In glucose dehydrogenase $\mathrm{Phl} p \mathrm{p}$, an even more astonishing increase in oxygen reactivity was observed upon changing

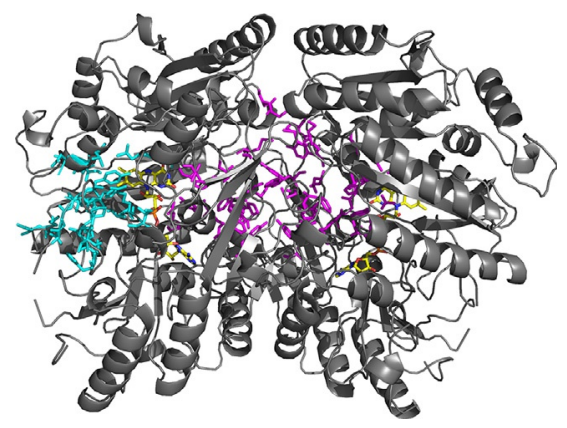

Fig. 9 VAO entry path for ligands and co-ligands. Residues involved in the predicted path for phenolic ligands at the subunit interface are shown as sticks (magenta), as are residues involved in the predicted path for co-ligands (cyan). The FAD cofactor is shown as sticks and colored in yellow. Modified from G. Gygli, M.F. Lucas, V. Guallar, W.J.H. van Berkel, The ins and outs of vanillyl alcohol oxidase: identification of ligand migration paths, PLoS Comput. Biol. 13 (2017) e1005787. 
the alternative gatekeeper Ile153 into Val [70]. Making the reversed change V169I in S-reticuline oxidase had a less drastic opposite effect [70]. Our PELE simulations suggested that in VAO, dioxygen reached its destination via the alternative gatekeeper site (Gly174) and the dimethylbenzene part of the flavin ring, and that dioxygen access required side chain movements of Tyr408 and Tyr51 [67].

$\mathrm{VAO}$ is the only characterized fungal member of the $4 \mathrm{PO}$ subgroup $[61,66]$ and until recently little was known about its distribution in fungi. $\mathrm{VAO}$ can be found in the carbohydrate active enzymes (CAZy) database as a separate family of auxiliary activities (AA4) involved in lignin breakdown [71]. Using gene sequences from the Mycocosm database annotated as AA4, the prevalence of VAO-like sequences was found not to follow fungal taxonomy [48]. Among the 93 putative VAOs found, 11 were present in basidiomycetous Agaricomycotina and 82 in ascomycetous Pezizomycotina (Fig. 10). Gene duplication appeared to have occurred in almost all fungal classes containing VAO homologs. All identified fungal VAO homologs lacked a N-terminal signal peptide, and were predicted to be peroxisomal or cytoplasmic, as proposed before for the enzyme from P. simplicissimum [14].

For this review, we updated the phylogenetic tree of fungal $4 \mathrm{PO}$ by adding more bacterial 4POs (Fig. 10). This phylogenetic tree contains all the amino acid sequences identified previously [48], with the addition of 100 hits from a motif search in the refseq database(https://www.genome. $\mathrm{jp} /$ tools/motif/) using the $4 \mathrm{PO}$ motif- $1(\mathrm{P}-\mathrm{x}-\mathrm{x}-\mathrm{x}-\mathrm{x}-\mathrm{S}-\mathrm{x}-\mathrm{G}-[\mathrm{RK}]-\mathrm{N}-\mathrm{x}-\mathrm{G}-$ Y-G-[GS]) and the sequences of FeeG and CndG. GilR from Streptomyces griseoflavus was used as an outgroup. Taxonomy was assigned using the taxonomy browser of the NCBI (https://www.ncbi.nlm.nih.gov/ taxonomy).

Three clades containing exclusively sequences from fungi were defined previously [48]. The first fungal clade contained sequences from Ascomycota (and one from Basidiomycota) most similar to the sequence of VAO from P. simplicissimum (Fig. 10, red clade). Members of this clade contained the octamerization loop [66] and residues Tyr51, Arg312, Arg398 and Glu410, involved in ligand migration [67]. The second fungal clade contained sequences from Ascomycota and Basidiomycota and could be split into two sub-clades, one without an octamerization loop and one with a very short octamerization loop (Fig. 10, yellow clade). The third fungal clade contained sequences from Ascomycota most dissimilar to VAO from $P$. simplicisimum. In the updated phylogenetic tree, these fungal sequences formed one clade with a group of bacterial 4POs (Fig. 10, blue clade). 


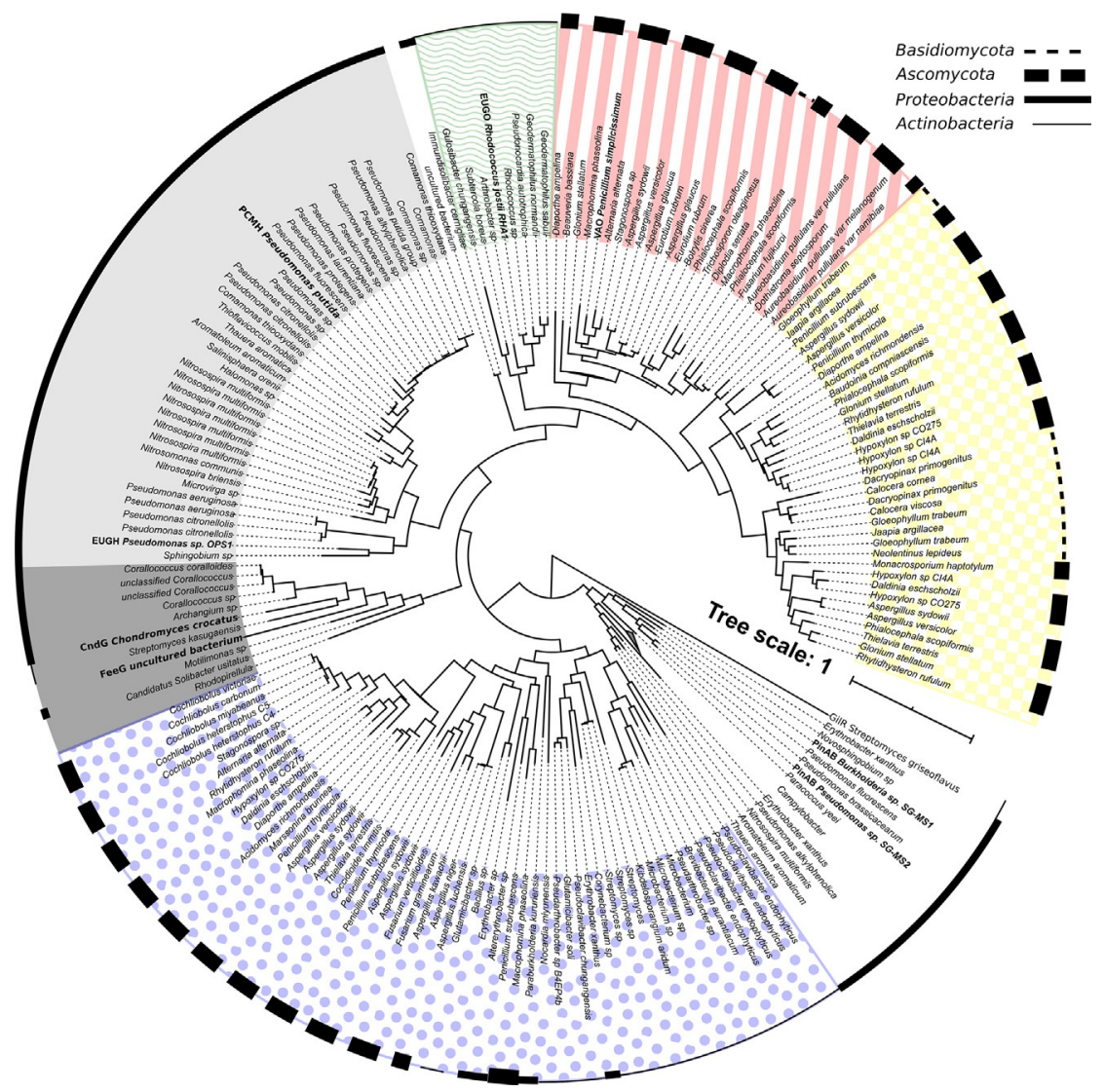

Fig. 10 Molecular phylogeny of 4POs. The phylogenetic tree was built as described previously [48], with the highest log likelihood (-22391.4490). Clades as defined previously [48] are shaded in red lines, yellow squares, blue dots, green waves or light gray. Newly identified clades are shaded in gray or white. The ring indicates fungal divisions (Basidiomycota and Ascomycota, thin and thick dashed lines, respectively) or bacterial phyla (Proteobacteria and Actinobacteria, thick and thin lines, respectively). Known enzymes are indicated in bold.

Putative 4POs in bacteria were found mostly in Proteobacteria and scarcely in Actinobacteria. Sequences from proteobacteria most similar to PCMH, unsurprisingly, lacked the octamerization loop, but contained a tyrosine involved in covalently binding the FAD cofactor in PCMH (position 384 in PCMH, light gray clade in Fig. 10), as did sequences in the more mixed clade (gray clade in Fig. 10). The remaining proteobacterial sequences contained the histidine involved in covalently binding the FAD cofactor in 
VAO (His422 in VAO, white clade in Fig. 10). In that clade, sequences from Campylobacter (indicated by a gray triangle), lacked almost 150 amino acids, including the catalytic base Asp170, and appeared to contain duplicated or triplicated elements, which might be due to misannotations or gene duplications.

Except for sequences from Campylobacter, Corallococcus and Archangium, all putative 4POs contained the Tyr-Tyr-Arg catalytic triad. His422 involved in covalent flavin binding, was found in most sequences. His61, implicated to be important for covalent flavinylation [32], was not conserved and often replaced by Tyr, Met or Phe. The active site base Asp170 was present in all sequences of the red clade, except for one Glu replacement. Sequences in all the other clades mainly contained a Ser or Ala at position 170. Interestingly, the majority of these sequences contained either a Thr or an Asp at position 457, which might be a good predictor for the absence or change in enantioselectivity for the reaction with 4-alkylphenols [43]. Again, the sequences from Campylobacter, Corallococcus and Archangium were an exception here, lacking the active site base at position 170 or 457 . The interested reader is referred to the full alignment provided as supplementary information.

When analyzing the genomic environment of the sequences in the red clade, no region of high synteny was found [48]. Together with the fact that the 4POs only partially followed the taxonomic fungal relationship, this supported the view that several of these species obtained these genes through horizontal transfer, most likely from bacteria. This theory explained the low frequency of presence of $\mathrm{VAO}$ in fungal genomes, and the phylogenetic diversity of the fungal VAO candidates. Fungi and bacteria separated about 4 billion years ago, much earlier than the separation between Actinobacteria and Proteobacteria (3.2 billion years ago) and the great oxidation event, which occurred between 2.4 and 2.1 billion years ago. Nevertheless, the actinobacterial EUGO clustered more closely with the fungal VAO than with the proteobacterial flavocytochrome PCMH (Fig. 10), indicating that the common ancestor of the 4PO subgroup was not a true oxidase.

Using additional motifs and fingerprint residues [67] will assist in assigning putative functions. Moreover, biochemical characterization of the identified 4POs will help to discriminate fungal and bacterial VAOs, EUGOs and PCMHs, especially for clades where no member has been characterized yet. Regarding the latter, it is of note that recently a new bacterial $4 \mathrm{PO}$ has been reported [72,73]. This inducible flavocytochrome, pinoresinol $\alpha$-hydroxylase from Pseudomonas sp. strain SG-M2 (PinAB), 
catalyzes the first step of a catabolic pathway in which the lignan(+)pinoresinol is degraded to protocatechuate (3,4-dihydroxybenzoate) and 2-methoxyhydroquinone(2-methoxy-1,4-dihydroxybenzene). The benzylic hydroxylation of $(+)$-pinoresinol occurs through a quinone-methide mechanism that is similar to that of VAO and the other characterized 4POs. PinAB contains, in contrast to PCMH and EUGH, a histidyl linked FAD as covalently bound prosthetic group [73], and resides in the white clade of the phylogenetic tree depicted in Fig. 10. The discovery of PinAB and its ortholog from Burkholderia sp. strain SG-MS1 [73] illustrates that much more can be learned from the biochemical characterization of the unexplored 4POs of the VAO/PCMH family.

\section{References}

[1] A. Fleming, On the antibacterial action of cultures of a Penicillium, with special reference to their use in the isolation of B. influenzae, Br. J. Exp. Pathol. 3 (1929) 3-13.

[2] E. de Jong, E.E. Beuling, R.P. van der Zwan, J.A.M. de Bont, Degradation of veratryl alcohol by Penicillium simplicissimum, Appl. Microbiol. Biotechnol. 34 (1990) 420-425.

[3] J. Overhage, A. Steinbüchel, H. Priefert, Highly efficient biotransformation of eugenol to ferulic acid and further conversion to vanillin in recombinant strains of Escherichia coli, Appl. Environ. Microbiol. 69 (2003) 6569-6576.

[4] J. Overhage, A. Steinbüchel, H. Priefert, Harnessing eugenol as a substrate for production of aromatic compounds with recombinant strains of Amycolatopsis sp. HR167, J. Biotechnol. 125 (2006) 369-376.

[5] R. Plaggenborg, J. Overhage, A. Loos, J.A.C. Archer, P. Lessard, A.J. Sinskey, A. Steinbüchel, H. Priefert, Potential of Rhodococcus strains for biotechnological vanillin production from ferulic acid and eugenol, Appl. Microbiol. Biotechnol. 72 (2006) 745-755.

[6] E. Ricklefs, M. Girhard, K. Koschorreck, M.S. Smit, V.B. Urlacher, Two-step one-pot synthesis of pinoresinol from eugenol in an enzymatic cascade, ChemCatChem 7 (2015) 1857-1864.

[7] E. Ricklefs, M. Girhard, V.B. Urlacher, Three-steps in one-pot: whole-cell biocatalytic synthesis of enantiopure (+)- and (-)-pinoresinol via kinetic resolution, Microb. Cell Fact. 15 (2016) 78.

[8] M.H.M. Habib, P.J. Deuss, N. Lončar, M. Trajkovic, M.W. Fraaije, A biocatalytic onepot approach for the preparation of lignin oligomers using an oxidase/peroxidase cascade enzyme system, Adv. Synth. Catal. 359 (2017) 3354-3361.

[9] T.A. Ewing, J. Kühn, S. Segarra, M. Tortajada, R. Zuhse, W.J.H. van Berkel, Multigram scale enzymatic synthesis of $(R)-1-\left(4^{\prime}\right.$-hydroxyphenyl)ethanol using vanillyl alcohol oxidase, Adv. Synth. Catal. 360 (2018) 2370-2376.

[10] E. de Jong, W.J.H. van Berkel, R.P. van der Zwan, J.A.M. de Bont, Purification and characterization of vanillyl-alcohol oxidase from Penicillium simplicissimum: a novel aromatic alcohol oxidase containing covalently bound FAD, Eur. J. Biochem. 208 (1992) 651-657.

[11] M.W. Fraaije, H. Roubroecks, W.R. Hagen, W.J.H. van Berkel, Purification and characterization of catalase/peroxidase from Penicillium simplicissimum, Eur. J. Biochem. 235 (1996) 192-198. 
[12] M.W. Fraaije, K.A. Sjollema, M. Veenhuis, W.J.H. van Berkel, Subcellular localization of vanillyl-alcohol oxidase in Penicillium simplicissimum, FEBS Lett. 422 (1998) 65-68.

[13] M.W. Fraaije, W.J.H. van Berkel, Catalytic mechanism of the oxidative demethylation of 4-(methoxymethyl)phenol by vanillyl-alcohol oxidase, J. Biol. Chem. 272 (1997) 18111-18116.

[14] M.W. Fraaije, M. Pikkemaat, W.J.H. van Berkel, Enigmatic gratuitous induction of the covalent flavoprotein vanillyl-alcohol oxidase in Penicillium simplicissimum, Appl. Environ. Microbiol. 63 (1997) 435-439.

[15] M.W. Fraaije, W.J.H. van Berkel, Novel enzyme makes vanillin for no apparent reason, ASM News 63 (1997) 206.

[16] M.W. Fraaije, C. Veeger, W.J.H. van Berkel, Substrate specificity of flavin-dependent vanillyl-alcohol oxidase from Penicillium simplicissimum: evidence for the production of 4-hydroxycinnamyl alcohols from 4-allylphenols, Eur. J. Biochem. 234 (1995) 271-277.

[17] H. Furukawa, M. Wieser, H. Morita, T. Sugio, T. Nagasawa, Purification and characterisation of vanillyl alcohol oxidase from Byssochlamys fulva V107, Biotechnol. Bioeng. 87 (1999) 285-290.

[18] R.H.H. van den Heuvel, M.W. Fraaije, C. Laane, W.J.H. van Berkel, Enzymatic synthesis of vanillin, J. Agric. Food Chem. 49 (2001) 2954-2958.

[19] M.W. Fraaije, R.H.H. van den Heuvel, J.C.A.A. Roelofs, W.J.H. van Berkel, Kinetic mechanism of vanillyl-alcohol oxidase with short-chain 4 alkylphenols, Eur. J. Biochem. 253 (1998) 712-719.

[20] F. Drijfhout, M.W. Fraaije, H. Jongejan, W.J.H. van Berkel, M.C.R. Franssen, Enantioselective hydroxylation of 4-alkylphenols by vanillyl-alcohol oxidase, Biotechnol. Bioeng. 59 (1998) 171-177.

[21] R.H.H. van den Heuvel, M.W. Fraaije, C. Laane, W.J.H. van Berkel, Regio- and stereospecific conversion of 4-alkylphenols by the covalent flavoprotein vanillyl-alcohol oxidase, J. Bacteriol. 180 (1998) 5646-5651.

[22] T.A. Ewing, A. van Noord, C.E. Paul, W.J.H. van Berkel, A xylenol orange-based screening assay for the substrate specificity of flavin-dependent para-phenol oxidases, Molecules 23 (2018) 164.

[23] A. Mattevi, M.W. Fraaije, A. Coda, W.J.H. van Berkel, Crystallization and preliminary $\mathrm{X}$-ray analysis of the flavoenzyme vanillyl-alcohol oxidase from Penicillium simplicissimum, Proteins 27 (1997) 601-603.

[24] A. Mattevi, M.W. Fraaije, A. Mozzarelli, L. Olivi, A. Coda, W.J.H. van Berkel, Crystal structure and inhibitor binding in the octameric flavoenzyme vanillyl-alcohol oxidase: the shape of the active-site cavity controls substrate specificity, Structure 5 (1997) 907-920.

[25] M.W. Fraaije, A. Mattevi, W.J.H. van Berkel, Mercuration of vanillyl-alcohol oxidase from Penicillium simplicissimum generates inactive dimers, FEBS Lett. 402 (1997) 33-35.

[26] J. Kim, J.H. Fuller, V. Kuusk, L.M. Cunane, Z. Chen, F.S. Matthews, W.S. McIntire, The cytochrome subunit is necessary for covalent FAD attachment to the flavoprotein subunit of p-cresol methylhydroxylase, J. Biol. Chem. 270 (1995) 31202-31209.

[27] L.M. Cunane, Z.-W. Chen, N. Shamala, F.S. Matthews, C.N. Cronin, W.S. McIntire, Structures of the flavocytochrome $p$-cresol methylhydroxylase and its enzyme-substrate complex: gated substrate entry and proton relays support the proposed catalytic mechanism, J. Mol. Biol. 295 (2000) 357-374.

[28] J.A.E. Benen, P. Sánchez-Torres, M.J.M. Wagemaker, M.W. Fraaije, W.J.H. van Berkel, J. Visser, Molecular cloning, sequencing, and heterologous expression of the vao $A$ gene from Penicillium simplicissimum CBS 170.90 encoding vanillyl-alcohol oxidase, J. Biol. Chem. 273 (1998) 7865-7872. 
[29] M.W. Fraaije, W.J.H. van Berkel, J.A.E. Benen, J. Visser, A. Mattevi, A novel oxidoreductase family sharing a conserved FAD binding domain, Trends Biochem. Sci. 23 (1998) 206-207.

[30] M. Mewies, W.S. McIntire, N.S. Scrutton, Covalent attachment of flavin adenine dinucleotide (FAD) and flavin mononucleotide (FMN) to enzymes: the current state of affairs, Protein Sci. 7 (1998) 7-20.

[31] M.W. Fraaije, R.H.H. van den Heuvel, W.J.H. van Berkel, A. Mattevi, Covalent flavinylation is essential for efficient redox catalysis in vanillyl-alcohol oxidase, J. Biol. Chem. 274 (1999) 35514-35520.

[32] M.W. Fraaije, R.H.H. van den Heuvel, W.J.H. van Berkel, A. Mattevi, Structural analysis of flavinylation in vanillyl-alcohol oxidase, J. Biol. Chem. 275 (2000) 38654-38658.

[33] A.J.R. Heck, W.J.H. van Berkel, New mass record, Spectrosc. Eur. 12-1 (2000) 6.

[34] W.J.H. van Berkel, R.H.H. van den Heuvel, C. Versluis, A.J.R. Heck, Detection of intact megaDalton protein assemblies of vanillyl-alcohol oxidase by mass spectrometry, Protein Sci. 9 (2000) 435-439.

[35] N. Tahallah, R.H.H. van den Heuvel, W.A.M. van den Berg, C.S. Maier, W.J.H. van Berkel, A.J.R. Heck, Cofactor-dependent assembly of the flavoenzyme vanillyl-alcohol oxidase, J. Biol. Chem. 277 (2002) 36425-36432.

[36] J. Jin, H. Mazon, R.H.H. van den Heuvel, A.J.R. Heck, D.B. Janssen, M.W. Fraaije, Covalent flavinylation of vanillyl-alcohol oxidase is an autocatalytic process, FEBS J. 275 (2008) 5191-5200.

[37] A. Hassan-Abdallah, R.C. Bruckner, G. Zhao, M.S. Jorns, Biosynthesis of covalently bound flavin: isolation and in vitro flavinylation of the monomeric sarcosine oxidase apoprotein, Biochemistry 44 (2005) 6452-6462.

[38] D.P.H.M. Heuts, N.S. Scrutton, W.S. McIntire, M.W. Fraaije, What's in a covalent bond? On the role and formation of covalently bound flavin cofactors, FEBS J. 276 (2009) 3405-3427.

[39] R.H.H. van den Heuvel, M.W. Fraaije, A. Mattevi, W.J.H. van Berkel, Asp170 is crucial for the redox properties of vanillyl-alcohol oxidase, J. Biol. Chem. 275 (2000) 14799-14808.

[40] R.H.H. van den Heuvel, M.W. Fraaije, W.J.H. van Berkel, Direction of the reactivity of vanillyl-alcohol oxidase with 4-alkylphenols, FEBS Lett. 481 (2000) 109-112.

[41] R.H.H. van den Heuvel, J. Partridge, C. Laane, P.J. Halling, W.J.H. van Berkel, Tuning the reactivity of enzyme-bound quinone methides by medium engineering, FEBS Lett. 503 (2001) 213-216.

[42] W.S. McIntire, D.J. Hopper, J.C. Craig, E.T. Everhart, R.V. Webster, M.J. Causer, T.P. Singer, Stereochemistry of 1-(4'-hydroxyphenyl)ethanol produced by hydroxylation of 4-ethylphenol by p-cresol methylhydroxylase, Biochem. J. 224 (1984) 617-624.

[43] R.H.H. van den Heuvel, M.W. Fraaije, A. Mattevi, M. Ferrer, W.J.H. van Berkel, Inversion of stereospecificity of vanillyl-alcohol oxidase, Proc. Natl. Acad. Sci. U. S. A. 97 (2000) 9455-9460.

[44] T.A. Ewing, Q.-T. Nguyen, R.C. Allan, G. Gygli, E. Romero, C. Binda, M.W. Fraaije, A. Mattevi, W.J.H. van Berkel, Two tyrosine residues, Tyr-108 and Tyr-503, are responsible for the deprotonation of phenolic substrates in vanillyl-alcohol oxidase, J. Biol. Chem. 292 (2017) 14668-14679.

[45] F. Lambert, J. Zucca, F. Ness, M. Aigle, Production of ferulic acid and coniferyl alcohol by conversion of eugenol using a recombinant strain of Saccharomyces cerevisiae, Flavour Fragr. J. 29 (2014) 14-21.

[46] G. Gygli, X. Sheng, F. Himo, W.J.H. van Berkel, Quantum chemical modelling of vanillyl alcohol oxidase, in: A Kaleidoscopic Look at Vanillyl Alcohol Oxidase, PhD thesis, Wageningen University, 2018, pp. 159-183. 
[47] R.H.H. van den Heuvel, W.A.M. van den Berg, S. Rovida, W.J.H. van Berkel, Laboratory-evolved vanillyl-alcohol oxidase produces natural vanillin, J. Biol. Chem. 279 (2004) 33492-33500.

[48] G. Gygli, R.P. de Vries, W.J.H. van Berkel, On the origin of vanillyl alcohol oxidases, Fungal Genet. Biol. 116 (2018) 24-32.

[49] G. Gygli, W.J.H. van Berkel, Vanillyl alcohol oxidases produced in Komagataella phaffii contain a highly stable noncovalently bound anionic FAD semiquinone, Biocatalysis 3 (2017) 17-26.

[50] C.H. Huang, W.L. Lai, M.H. Lee, C.J. Chen, A. Vasella, Y.C. Tsai, S.H. Liaw, Crystal structure of glucooligosaccharide oxidase from Acremonium strictum: a novel flavinylation of 6-S-cysteinyl, 8 $8-N^{1}$-histidyl FAD, J. Biol. Chem. 280 (2005) 38831-38838.

[51] N.G.H. Leferink, D.P.H.M. Heuts, M.W. Fraaije, W.J.H. van Berkel, The growing VAO flavoprotein family, Arch. Biochem. Biophys. 474 (2008) 292-301.

[52] K. Brandt, S. Thewes, J. Overhage, H. Priefert, A. Steinbüchel, Characterization of the eugenol hydroxylase genes $\left(e h \gamma A / e_{\gamma} B\right)$ from the new eugenol-degrading Pseudomonas sp. strain OPS1, Appl. Microbiol. Biotechnol. 56 (2001) 724-730.

[53] H. Priefert, J. Overhage, A. Steinbüchel, Identification and molecular characterization of the eugenol hydroxylase genes $(e h y A /$ ehyB $)$ of Pseudomonas sp. strain HR199, Arch. Microbiol. 172 (1999) 354-363.

[54] J. Jin, H. Mazon, R.H.H. van den Heuvel, D.B. Janssen, M.W. Fraaije, Discovery of a eugenol oxidase from Rhodococcus sp. strain RHA1, FEBS J. 274 (2007) 2311-2321.

[55] A. Winkler, F. Hartner, T.M. Kutchan, A. Glieder, P. Macheroux, Biochemical evidence that berberine bridge enzyme belongs to a novel family of flavoproteins containing a bi-covalently attached FAD cofactor, J. Biol. Chem. 281 (2006) 21276-21285.

[56] A. Winkler, K. Motz, S. Riedl, M. Puhl, P. Macheroux, K. Gruber, Structural and mechanistic studies reveal the functional role of bicovalent flavinylation in berberine bridge enzyme, J. Biol. Chem. 284 (2009) 19993-20001.

[57] W.P. Dijkman, G. de Gonzalo, A. Mattevi, M.W. Fraaije, Flavoprotein oxidases: classification and applications, Appl. Microbiol. Biotechnol. 97 (2013) 5177-5188.

[58] E.W. van Hellemond, N.G.H. Leferink, D.P.H.M. Heuts, M.W. Fraaije, W.J.H. van Berkel, Occurrence and biocatalytic potential of carbohydrate oxidases, Adv. Appl. Microbiol. 60 (2006) 17-54.

[59] B. Daniel, B. Konrad, M. Toplak, M. Lahham, J. Messenlehner, A. Winkler, P. Macheroux, The family of berberine bridge enzyme-like enzymes: a treasure-trove of oxidative reactions, Arch. Biochem. Biophys. 632 (2017) 88-103.

[60] M.M. Kopacz, M.W. Fraaije, Turning a monocovalent flavoprotein into a bicovalent flavoprotein by structure-inspired mutagenesis, Bioorg. Med. Chem. 22 (2014) $5621-5627$

[61] T.A. Ewing, M.W. Fraaije, A. Mattevi, W.J.H. van Berkel, The VAO/PCMH flavoprotein family, Arch. Biochem. Biophys. 632 (2017) 104-117.

[62] S.F. Brady, C.J. Chao, J. Clardy, New natural product families from an environmental DNA (eDNA) gene cluster, J. Am. Chem. Soc. 124 (2002) 9968-9969.

[63] S. Rachid, O. Revermann, C. Dauth, U. Kazmaier, R. Müller, Characterization of a novel type of oxidative decarboxylase involved in the biosynthesis of the styryl moiety of chondrochloren from an acylated tyrosine, J. Biol. Chem. 285 (2010) 12482-12489.

[64] Q.-T. Nguyen, G. de Gonzalo, C. Binda, A. Rioz-Martínez, A. Mattevi, M.W. Fraaije, Biocatalytic properties and structural analysis of eugenol oxidase from Rhodococcus jostii RHA1: a versatile oxidative biocatalyst, Chembiochem 17 (2016) 1359-1366.

[65] M. Habib, M. Trajkovic, M.W. Fraaije, The biocatalytic synthesis of syringaresinol from 2,6-dimethoxy-4-allylphenol in one-pot using a tailored oxidase/peroxidase system, ACS Catal. 8 (2018) 5549-5552. 
[66] T.A. Ewing, G. Gygli, W.J.H. van Berkel, A single loop is essential for the octamerization of vanillyl alcohol oxidase, FEBS J. 283 (2016) 2546-2559.

[67] G. Gygli, M.F. Lucas, V. Guallar, W.J.H. van Berkel, The ins and outs of vanillyl alcohol oxidase: identification of ligand migration paths, PLoS Comput. Biol. 13 (2017) e1005787.

[68] R. Baron, C. Riley, P. Chenprakhon, K. Thotsaporn, R.T. Winter, A. Alfieri, F. Forneris, W.J.H. van Berkel, P. Chaiyen, M.W. Fraaije, A. Mattevi, J.A. McCammon, Multiple pathways guide oxygen diffusion into flavoenzyme active sites, Proc. Natl. Acad. Sci. U. S. A. 106 (2009) 10603-10608.

[69] N.G.H. Leferink, M.W. Fraaije, H.J. Joosten, P.J. Schaap, A. Mattevi, W.J.H. van Berkel, Identification of a gatekeeper residue that prevents dehydrogenases from acting as oxidases, J. Biol. Chem. 284 (2009) 4392-4397.

[70] D. Zafred, B. Steiner, A.R. Teufelberger, A. Hromic, P.A. Karplus, C.J. Schofield, S. Wallner, P. Macheroux, Rationally engineered flavin-dependent oxidase reveals steric control of dioxygen reduction, FEBS J. 282 (2015) 3060-3074.

[71] A. Levasseur, E. Drula, V. Lombard, P.M. Coutinho, B. Henrissat, Expansion of the enzymatic repertoire of the CAZy database to integrate auxiliary redox enzymes, Biotechnol. Biofuels 6 (2013) 41.

[72] M. Shettigar, S. Balotra, D. Cahill, A.C. Warden, M.J. Lacey, H.E. Kohler, D. Rentsch, J.G. Oakeshott, G. Pandey, Isolation of the (+)-pinoresinol-mineralizing Pseudomonas sp. strain SG-MS2 and elucidation of its catabolic pathway, Appl. Environ. Microbiol. 84 (2018) e02531-17.

[73] M. Shettigar, S. Balotra, A. Kasprzak, S.L. Pearce, M.J. Lacey, M.C. Taylor, J.W. Liu, D. Cahill, J.G. Oakeshott, G. Pandey, Oxidative catabolism of (+)-pinoresinol is initiated by an unusual flavocytochrome encoded by translationally coupled genes within a cluster of (+)-pinoresinol-coinduced genes in Pseudomonas sp. strain SG-MS2, Appl. Environ. Microbiol. 86 (2020) e00375-20. 